\title{
Interactive presentation digital tool Mentimeter perceived as accessible and beneficial for exam preparation by medical students
}

\begin{abstract}
Victoria C. Kuritza ${ }^{1^{\dagger}} \quad$ Daniel P. Cibich ${ }^{\dagger} \quad$ Kashif A. Ahmad A $^{3,4^{*}}$
Abstract: As medical students are responsible for understanding vast medical content in a short amount of time, instructors have shifted their focus to include flipped classroom model and use innovative educational tools in class to facilitate stronger comprehension and critical thinking. While there are many audience response systems (ARS) available, the cost to the institution and students in the form of licenses, and installation of hardware can be a significant problem. Besides, faculty can show resistance in adopting these tools. Mentimeter is a web-based ARS that is low cost and is available on any device anytime. We wanted to inquire about its impact on learning in our medical students since course evaluations are usually retrievable at the end of course. By analyzing satisfaction surveys, this study looked at the utilization of Mentimeter in a medical physiology course. Medical students overwhelmingly agreed that Mentimeter is a useful tool for exam preparation in clarifying difficult concepts and appreciated an instructor-led readiness assessment several days before their first exam. We believe that the use of this application can help explain basic concepts, make office hours more constructive, and bring a paradigm shift in readiness assessment for medical students in both preclinical and clinical curriculum.
\end{abstract}

Keywords: Mentimeter, flipped classroom, Audience Response System, student engagement, physiology, readiness assessment

\section{Introduction}

The relative impracticality of significant audience participation and interaction is a considerable challenge of larger groups, such as lecture halls or larger conference groups. Not only is it more difficult for instructors to gauge student understanding of material, but students may also feel uncomfortable raising their hands to ask questions for clarification of material. An initial solution to this issue arose with the development of a Classroom Communicating System (CCS), also more generally called an Audience Response System (ARS). The first CCS called Classtalk was developed in 1985 and allowed

\footnotetext{
Received: November 11, 2019 Accepted: March 28, 2020 Published: April 1, 2020

* Correspondence to: Kashif A. Ahmad. Carle Illinois College of Medicine, University of Illinois-Urbana Champaign, Champaign, IL 61820, USA \& Department of Medica Information Science, University of Illinois College of Medicine-Urbana Champaign, Urbana,

L 6180, USA; Email: kahmad@illinois.edu; kahmad@berkeley.edu

${ }^{\dagger}$ The first two authors had equal contribution to this work

${ }^{1}$ University of Illinois College of Medicine-Rockford, IL 61107, USA

${ }^{2}$ University of Illinois College of Medicine-Peoria, IL 61605, USA

${ }^{3}$ Carle Illinois College of Medicine, University of Illinois-Urbana Champaign, Champaign, IL 61820, USA

${ }^{4}$ Department of Medical Information Science, University of Illinois College of MedicineUrbana Champaign, Urbana, IL 6180, USA

Citation: Kuritza VC, Cibich DP and Ahmad KA. Interactive presentation digital tool Mentimeter perceived as accessible and beneficial for exam preparation by medical students. Adv Educ Res Eval, 2020, 1(2): 63-67.

Copyright: $\odot 2020$ Kashif A. Ahmad, et al. This is an open access article distributed under the terms of the Creative Commons Attribution License, which permits unrestricted use, distribution, and reproduction in any medium, provided the original author and source are
} credited. students to input answers with a graphing calculator. A hard-wired connection would link the calculators with the instructor's command console, a MacIntosh computer ${ }^{[1]}$. Other ARS tools such as Poll Everywhere, EduCue PRS, eInstruction CPS, and I-Clicker increased their presence at the turn of the millennium. These tools require students to have "remotes" or "clickers" to input answers and a base to receive them - no hardwired connection is required. Many of tools are still in use, although the latest generation of ARSs is emerging, requiring only a Wi-Fi connection and a computer, tablet, or smartphone. Online websites such as Mentimeter and TopHat serve as the "middleman" to receive, tabulate, and present the data collected.

A paradigm shift in contemporary medical education has been away from didactic lectures and towards more active forms, such as Problem Based Learning (PBL) and Team Based Learning (TBL), which tend to utilize smaller student groups. Yet, it is challenging to envision a curriculum devoid of all didactic lectures. Therefore, Audience Response Systems have become a possible tool for educators to increase comprehension and retention of didactic lectures. An ARS could also be utilized in PBL and TBL sessions as well.

There are several benefits to using an ARS. Most notably, it enables educators to assess the comprehension of their entire audience at any point. ARSs offer the abil- 
ity to quickly tabulate answers, the possibility of taking student attendance, the opportunity for a more engaging atmosphere to promote audience participation and limiting effects of crowd psychology. Since students cannot visualize how fellow students are answering, their answers are less influenced by group thinking. It is akin to taking a poll by show of hands, but with everyone's head down.

Few aspects give an educator more anxiety than the fear that the audience is not understanding the topic as intended. By polling anonymously and in real time, an ARS gives educators a way to assess students' knowledge more accurately. Since the initial development of Classtalk, the impact of using an ARS has been seen in many different academic areas. The literature is well documented with various reports of "clicker" units serving as effective tools for learning ${ }^{[2]}$. ARSs have demonstrated a positive effect on attention and enthusiasm ${ }^{[3]}$, more time spent active in lecture, improved learning, enhanced questioning from students, and awareness of what colleagues are thinking ${ }^{[4]}$. Studies have also shown the use of personal cell phones instead of a clicker to be an enjoyable and interactive ARS tool ${ }^{[5,6]}$. Finally, data exists on ARS effectiveness in Continuing Medical Education for physicians and other healthcare professionals ${ }^{[3]}$.

Limited data exist, however, evaluating the effectiveness of ARSs on medical school education and assessment. The aim of this project is to examine the usefulness of the novel web-based tool Mentimeter (www.mentimeter.com), a collaborative and interactive online ARS, in preparing first-year medical students for physiology exams. We hypothesize that Mentimeter and similar ARS tools could have a significant effect on student preparedness for physiology exams and could tremendously improve retention of physiology knowledge. We chose Mentimeter because of its visual appeal, it assigns creative icons to students without identifying them and ease of use for instructors. The use of Mentimeter will promote mastery learning a teaching and learning strategy based on the premise that students will achieve a high level of understanding in each domain if they are given enough time.

\section{Methods}

Participants from a first-year medical physiology class at the University of Illinois College of Medicine (UrbanaChampaign, IL) volunteered for this investigation. Prior to the investigation, a deliberate model was employed to maximize student learning. After lecture material was presented and several days prior to the first block exam (formative assessment), students completed their first Readiness Assessment (using Mentimeter), consisting of 30 Mentimeter multiple-choice questions. Several days between the Readiness Assessment and the Formative Assessment were crucial to solidify understanding of the material in different ways, which we have called the Mentimeter Model (Figure 1). For example, during the Readiness Assessment, a class-wide discussion of both incorrect responses and correct responses encouraged students to reflect on difficult material and think about what students needed to continue studying. Additionally, students still had time to come in for office hours to further clarify material or watch videos created by the same instructor (KA).

After the formative assessment, an IRB approved survey was conducted in our own Benware, Inc, where students were asked to rate statements on a 1 to 5 Likert scale where $1=$ Strongly Disagree, $2=$ Disagree, $3=$ Neutral, $4=$ Agree, $5=$ Strongly Agree. Additionally, after the survey questions, students were given the opportunity to explain why they enjoyed or did not enjoy Mentimeter in a brief narrative, as well as give constructive criticism regarding the course itself. The course received high rating and the overall course evaluations are not included in this manuscript.

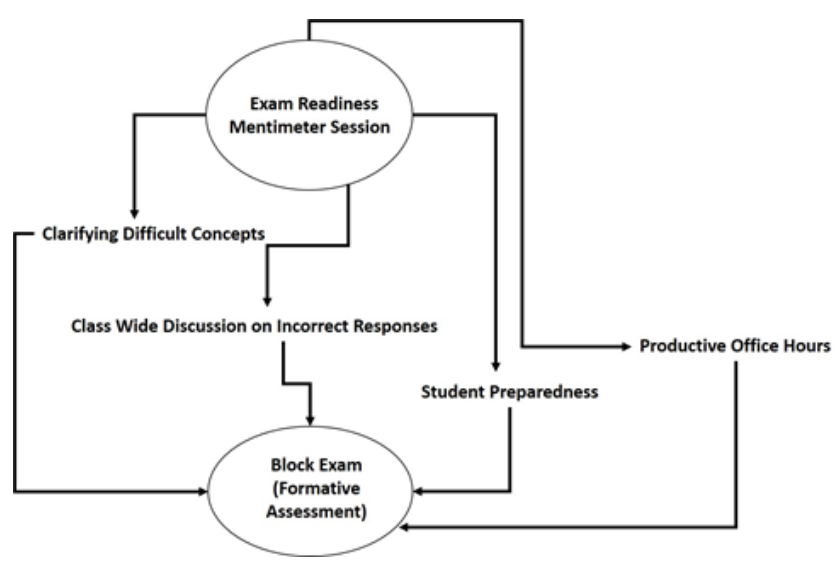

Figure 1. Beneficial approach of a Mentimeter session leading to a formative assessment

\section{Results}

The following percentages of students reported either a 4 or 5 when asked about the following metrics of Mentimeter: $76.7 \%(n=43)$ found it "helped prepare [students] for their exam", $80.9 \%(n=42)$ found it "beneficial", and $87.5 \%(\mathrm{n}=40)$ found it "accessible via [their] cell phones". (see Table 1)

The first survey question asked whether students felt that the "readiness assessment" session helped prepare them for the exam or measured their level of preparation. 


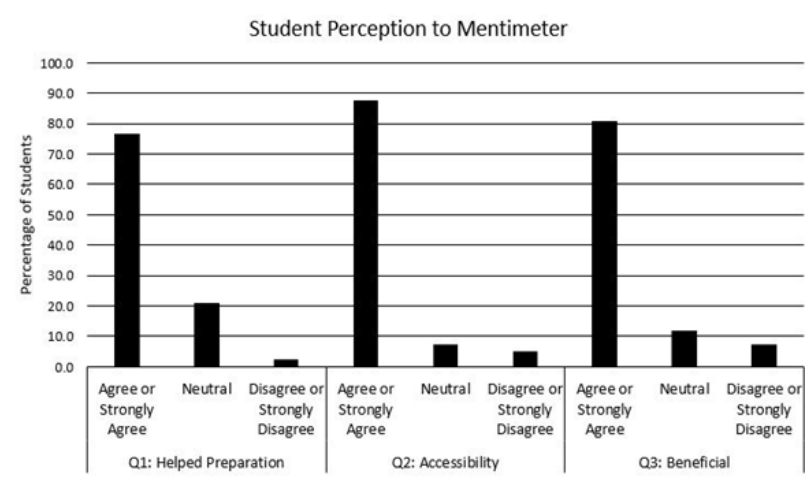

Figure 2. Percentages of student responses

$76.7 \%$ of students $(n=43)$ either Strongly Agreed or Agreed (i.e. gave a 4 or 5 rating, respectively), $20.9 \%$ of students were Neutral (i.e. gave a 3 rating), and $2.3 \%$ of students either Disagreed or Strongly Disagreed (i.e. gave a 2 or 1 rating, respectively) $(M=4.3, S D=0.86)$. The second survey question asked whether the Mentimeter program was accessible via their cell phones. $87.5 \%$ of respondents $(\mathrm{n}=40)$ either Strongly Agreed or Agreed, $7.5 \%$ of respondents were Neutral, and $5 \%$ of respondents either Disagreed or Strongly Disagreed $(M=4.4, S D=$ 0.98 ). The final survey question evaluated whether the Mentimeter quizzes were beneficial. To this, $81 \%$ of students $(n=42)$ Strongly Agreed or Agreed, $11.9 \%$ were Neutral, and 7.1\% Disagreed or Strongly Disagreed $(M=$ $0.1, S D=0.96$ ). (see Figure 2)

\section{Discussion}

$76.7 \%(\mathrm{n}=43)$ Of students found that Mentimeter "helped prepare [students] for their exam", $80.9 \%(\mathrm{n}=42)$ found it "beneficial", and $87.5 \%(n=40)$ found it "accessible via [their] cell phones". This data suggests that the utilization of an ARS, specifically Mentimeter, was overall well-received by medical students. Combining the survey data with encouraging student narratives, these data suggest that using Mentimeter could be a beneficial tool for educators to use, especially when preparing for exams or assessing students' understanding of historically challenging concepts (as medical physiology tends to be). The students commented on the value of these tools appreciating the Mentimeter quizzes that provided instant real time feedback (Table 2) on their knowledge retention and potential areas to review before exams. We hypothesize the effect of Mentimeter will be significant with respect to student preparedness for physiology exams and could tremendously improve retention of physiology knowledge. There are many observed benefits to using Mentimeter in the classroom setting. Mentimeter is a low cost, online software that can be utilized by instructors in any classroom with internet access. It engages students by assigning them an avatar, and awards points based on accuracy and speed of answers submitted. These are unique aspects when compared to other ARSs. I-Clicker, another popular ARS, requires students to buy their own device, register it with the school, and bring it to class. It also requires the specialized base, or receiver, to be preinstalled in the classroom, and this presents a barrier for instructors limited by departmental budgets or scheduling constraints for ARS-equipped classrooms. An additional benefit of Mentimeter is that it includes multiple different features to promote learning at different levels. For example, instructors can use multiple choice-style questions or short-answer questions and can mix-and-match question styles as they please. Alternatively, additional options such as developing word clouds and being able to rate items on a scale exist to offer a more dynamic learning interface. This is yet another way an ARS such as I-Clicker is limited. TopHat is another popular web-based ARS that allows students to use their laptop or smartphone like Mentimeter. However, TopHat requires students or institutions to purchase a four-month, twelve month or lifetime subscription. As the basic version of Mentimeter

Table 1. Summary of questionnaire results for students who used Mentimeter ARS. $M=$ Mean (based on the five-point Likert scale, with $1=$ Strongly Disagree and $5=$ Strongly Agree), $S D=$ Standard Deviation of the Mean

\begin{tabular}{|c|c|c|c|c|c|c|}
\hline Question & $\begin{array}{l}\text { Participants } \\
\text { (n) }\end{array}$ & Agree $^{1}$ & Neutral & Disagree $^{2}$ & $M^{3}$ & $S D$ \\
\hline $\begin{array}{l}\text { Rate how well the "readiness assessment" session } \\
\text { helped prepare you for the exam or measured your } \\
\text { level of preparation? }\end{array}$ & $\mathrm{n}=43$ & $76.70 \%$ & $20.90 \%$ & $2.30 \%$ & 4.3 & 0.86 \\
\hline $\begin{array}{l}\text { Rate the accessibility of Mentimeter via your cell } \\
\text { phones? }\end{array}$ & $\mathrm{n}=40$ & $87.50 \%$ & $7.50 \%$ & $5 \%$ & 4.4 & 0.98 \\
\hline Rate how beneficial the Mentimeter quizzes were? & $\mathrm{n}=42$ & $81 \%$ & $11.90 \%$ & $7.10 \%$ & 4.1 & 0.96 \\
\hline
\end{tabular}


Table 2. Summary of student narratives

\begin{tabular}{|c|c|}
\hline Question & Response(s) ${ }^{1}$ \\
\hline $\begin{array}{l}\text { Please provide any comments or constructive } \\
\text { criticisms that could benefit the content or } \\
\text { presentation of the course. }\end{array}$ & $\begin{array}{l}\text { "Mentimeter was such a great idea because it got us excited to take practice } \\
\text { questions and compete against each other while figuring out what material we } \\
\text { need to spend more time on. I made sure I never missed those days (way better } \\
\text { than iClicker). He put the time in to make sure we had a solid grasp on the } \\
\text { information." }\end{array}$ \\
\hline \multirow[t]{2}{*}{$\begin{array}{l}\text { Please provide any other helpful information about } \\
\text { the active learning strategies utilized in the course. }\end{array}$} & $\begin{array}{l}\text { "All the active learning tools used were helpful including the PBLs and } \\
\text { mentimeter readiness assessments." }\end{array}$ \\
\hline & $\begin{array}{l}\text { - "I thought that the educreation videos were a great addition to the course, } \\
\text { and the mentimeter quizzes were both fun and educational." } \\
\text { - "Questions! The mentimeter and the questions Dr.KA prompted us with in } \\
\text { class were huge in my success in the course. Recall is everything when you're } \\
\text { learning so much information and he did a great job with that." }\end{array}$ \\
\hline \multirow{3}{*}{$\begin{array}{l}\text { What aspects of the course were most valuable for } \\
\text { your learning? }\end{array}$} & • "The lectures and mentimeter quizzes were very valuable for my learning." \\
\hline & $\begin{array}{l}\text { - "Mentimeter was definitely beneficial. Also using one reference source book, } \\
\text { Costanzo, was extremely helpful because all of the information was localized } \\
\text { to one place." }\end{array}$ \\
\hline & $\begin{array}{l}\text { - "The readiness assessments with Mentimeter have been a great way for me to } \\
\text { evaluate how much of the material I've learned and potential areas to focus on } \\
\text { before the exam." }\end{array}$ \\
\hline
\end{tabular}

Note: 1 . Responses mentioning Mentimeter, both positively or negatively, were included

is available to instructor for a nominal fee, Mentimeter users are not limited by either a subscription or hardware requirement and have the option to use more features than traditionally available. While certainly other online ARSs exist and their use is questionable, we observed great student satisfaction with Mentimeter, and hope that these findings promote further research into Mentimeter and using ARSs for better knowledge retention among medical students. Our data further corroborates a previous ARS study which found the aspects students liked most were that it: encouraged student participation, provided opportunity for self-assessment, and facilitated mutual awareness among classmates. This same study also found cost to be one of the biggest student complaints ${ }^{[7]}$.

Moreover, as the clinical environment has been changing, the methods of medical education have been adapting to these new demands. Previous models based on Osler merged clinical exposure with didactic lectures. However, as average inpatient hospital stays shorten and patients tend to present with multi-organ system conditions, these traditional models are being re-evaluated ${ }^{[8]}$. Currently, most medical schools are striving to identify gaps in education and create solutions to produce the next generation of physicians. One major goal is focused on how to achieve competency despite growing volume of knowledge and prevalence of chronic, multi-organ system conditions ${ }^{[9,10]}$. Mentimeter could certainly play a role in this regard, as we observe it to be regarded posi- tively among those in the medical field. Mentimeter could also be incorporated with other, new educational technology, such as Educreations video software. Educreations allows instructors to upload interactive lectures with simultaneous annotations and narrations and has demonstrated high student satisfaction from work submitted by the corresponding author ${ }^{[11,12]}$. Therefore, students could be assigned or supplemented with Educreations videos ahead of a Mentimeter readiness assessment on the most challenging concepts. Although data on effectiveness of ARS tools in certain disciplines appear to show a moderate effect ${ }^{[13]}$, our proposal and concept align with published research on technology assisted learning and initial studies that supported the use of the innovative tools ${ }^{[14]}$. Our own research on use of digital cognitive apprenticeship highlights the need for looking at innovative ways of teaching in medical education ${ }^{[15]}$. As more medical schools reevaluate their mode of instruction and adopt active learning ${ }^{[16]}$ in accordance with licensing medical boards, innovation in ARS will serve great purpose in enhancing the student's learning experience and furthermore the application can help in improving explanation of basic concepts in medical education.

\section{Conclusion}

Initial data has demonstrated Mentimeter and other similar tools are useful in medical education that are positively received by students and provide platform to medi- 
cal educators who seek innovation in medical education. We encourage the use of novel education tools like Mentimeter that initially could seem daunting to use by faculty but when adopted they can significantly enhance student learning.

\section{Limitations}

While this pilot study was limited to three survey questions, the results show promising results to further investigate effectiveness of this learning platform. Follow up studies could include utilization of Mentimeter in other courses both preclinical and clinical settings and application in residency programs or continuing education classes. As the volume necessary to be taught in medicine increases, better teaching tools and strategies must be identified and utilized. An easy-to-implement ARS, such as Mentimeter, shows promise that it could be one part of the solution.

\section{Acknowledgements}

The authors would like to thank the M1 class of 2020 at University of Illinois Urbana Champaign-College of Medicine for participation in satisfaction surveys.

\section{Declaration of Interest}

Mentimeter has supplied a free subscription to the authors to have access to all features. Authors have no financial stake in Mentimeter nor did they receive any monetary compensation for this study. The sole purpose is to familiarize faculty on novel applications in educational technology.

\section{References}

[1] Beatty ID. Transforming student learning with classroom communication systems. Educause Center for Applied Research, 2004, 3: 1-13. https://arxiv.org/ftp/physics/papers/0508/0508129.pdf

[2] Dufresne RJ, Gerace WJ, Leonard WJ, et al. Classtalk: A Classroom Communication System for Active Learning. Journal of Computing in Higher Education, 1996, 7(2): 347. https://doi.org/10.1007/BF02948592

[3] Ding L, Reay NW, Lee A, et al. Are we asking the right questions? Validating clicker question sequences through student interviews. American Journal of Physics, 2009, 77(7): 643-650. https://doi.org/10.1119/1.3116093

[4] Miller RG, Ashar B and Getz KJ. Evaluation of an audience response system for the continuing education of health pro- fessionals. Journal of Continuing Education in the Health Professions, 2003, 23(2): 109-115. https://doi.org/10.1002/chp.1340230208

[5] Uhari M, Renko M and Soini H. Experiences of using an interactive audience response system in lectures. Biomed Central Medical Education, 2003, 3(1): 12. https://doi.org/10.1186/1472-6920-3-12

[6] Tremblay E. Educating the Mobile Generation - using personal cell phones as audience response systems in postsecondary science teaching. Journal of Computers in Mathematics and Science Teaching, 2010, 29(2): 217-227.

[7] Reimers S and Stewart N. Using SMS text messaging for teaching and data collection in the behavioral sciences. Behavior Research Methods, 2009, 41(3): 675-681. https://doi.org/10.3758/BRM.41.3.675

[8] Graham CR, Tripp TR, Seawright L, et al. Empowering or compelling reluctant participators using audience response systems. Active Learning in Higher Education, 2007, 8(3): 233-258. https://doi.org/10.1177/1469787407081885

[9] Norman G. Medical education: past, present and future. Perspectives on Medical Education, 2012, 1(1): 6-14. https://doi.org/10.1007/s40037-012-0002-7

[10] Skochelak SE. A Decade of Reports Calling for Change in Medical Education: What Do They Say? Academic Medicine, 2010, 85(9): 26-33. https://doi.org/10.1097/ACM.0b013e3181f1323f

[11] Crosson FJ, Leu J, Roemer BM, et al. Gaps In Residency Training Should Be Addressed To Better Prepare Doctors For A Twenty-First-Century Delivery System. Health Affairs, 2011, 30(11): 2142-2148. https://doi.org/10.1377/hlthaff.2011.0184

[12] Ahmad K and Hinck G. The Impact of a Course-Content Creation Tool (Educreations ${ }^{\mathrm{TM}}$ ) on Student Learning in a Physiology Course. Medical Science Educator, 2016, 26(3): 275-277. https://doi.org/10.1007/s40670-016-0259-2

[13] Castillo-Manzano JI, Castro-Nuño M, López-Valpuesta L et al. Measuring the effect of ARS on academic performance: A global meta-analysis. Computers \& Education, 2016, 96: 109-121. https://doi.org/10.1016/j.compedu.2016.02.007

[14] Wenk L. Technology-Assisted Active Learning In Large Lectures, A. P. McNeal and C. D'Avanzo, eds., StudentActive Science: Models of Innovation in College Science Teaching. Philadelphia: Saunders College Publishing, 1997: 431-451.

[15] Adham ZO, Grenda PJ and Ahmad KA. Developing a digital algorithm for cognitive apprenticeship in first year medical school physiology. Medical Science Educator, 2018, 28: 119-124. https://doi.org/10.1007/s40670-017-0517-y

[16] Mazur E. Peer Instruction: A User's Manual, Upper Saddle River, N.J: Prentice Hall, 1997. https://doi.org/10.1063/1.881735 